\title{
THE ANATOMY OF THE SEPTAL PERFORATING ARTERIES IN NORMAL AND CONGENITALLY MALFORMED HEARTS
}

\author{
A. R. Hosseinpour, MD, FRCS \\ R. H. Anderson, MD, FRCPath \\ S. Y. Ho, PhD, FRCPath
}

Background: Many cardiac operations involve incisions and sutures on or near the ventricular septum. These jeopardize the septal perforating arteries. Our aim was to provide guidelines for the surgeon to predict the site of these vessels.

Methods and results: We dissected 50 hearts. In 16 of these we also conducted histologic examination of the area of the septum containing the atrioventricular node, the penetrating bundle (of His), and the branching atrioventricular bundle to elucidate the source of the vascular supply to these structures. The major perforating septal arteries arise from the superior interventricular artery or, in hearts with a rudimentary right ventricle, from the superior delimiting artery. The first is usually the largest. The location of this artery can be predicted relative to the position of the medial papillary muscle. In abnormal hearts, holes within the ventricular septum in the presence of a well-developed muscular outlet septum were found to deviate the path of the septal perforating arteries in a predictable manner. The triangular area bordered by the margin of the ventricular septal defect, the muscular outlet septum, and the medial papillary muscle is free of major perforating arteries. The histologic studies showed that the conduction tissues at the base of the ventricles tend to receive their blood supply from arteries arising from the inferior interventricular artery, except in double-inlet left ventricle, in which the arterial supply is from the right-sided delimiting artery.

Conclusion: The location of the first superior septal perforating artery is predictable in many cases. Its course leaves a triangular area on the muscular ventricular septum that is free of major arteries. ( $\mathrm{J}$ Thorac Cardiovasc Surg 2001;121:1046-52)
$\mathrm{T}_{\mathrm{s}}^{\mathrm{h}}$ he perforating arteries that nourish the ventricular septum and the atrioventricular conduction tissues are placed at risk during operations that involve incisions in the region of the normal ventricular septum or in its immediate vicinity in the outflow tract of the right ventricle. ${ }^{1}$ Such incisions involving the outflow tracts are now an integral part of many surgical procedures used in the repair of congenital heart defects. To the best

From the National Heart and Lung Institute, Royal Brompton Campus, Imperial College of Science, Technology and Medicine, London, United Kingdom.

Dr Hosseinpour is currently at the Department of Cardiothoracic Surgery, Papworth Hospital, Cambridge; Professor Anderson is now at the Cardiac Unit, Institute of Child Health, London.

This project was made possible by a project grant from the British Heart Foundation (PG 97137).

Copyright (c) 2001 by The American Association for Thoracic Surgery

0022-5223/2001 $\$ 35.00+0 \quad \mathbf{1 2 / 1 / 1 1 3 6 0 4}$

doi: $10.1067 / \mathrm{mtc} .2001 .113604$ of our knowledge, however, little information is available to permit the surgeon to predict the exact site of the septal perforating arteries to avoid damaging them. In the normal heart the perforating arteries arise from the 2 major epicardial arteries that delimit the location of the muscular ventricular septum. ${ }^{1-3}$ These are the so-called anterior and posterior descending arteries, although in reality their interrelationships are more accurately described as superior and inferior. In hearts with 1 dominant and 1 incomplete and hypoplastic ventricle, the comparable epicardial arteries are better described as "delimiting" arteries. The superior perforating septal arteries, which arise from the superior interventricular or delimiting arteries, are significantly larger than their inferior counterparts. Despite the studies that established the origin and distribution of these septal perforating arteries, ${ }^{1-3}$ no accurate method has been proposed to permit the surgeon to predict their location when working in the operating room. Similarly, little is known about 


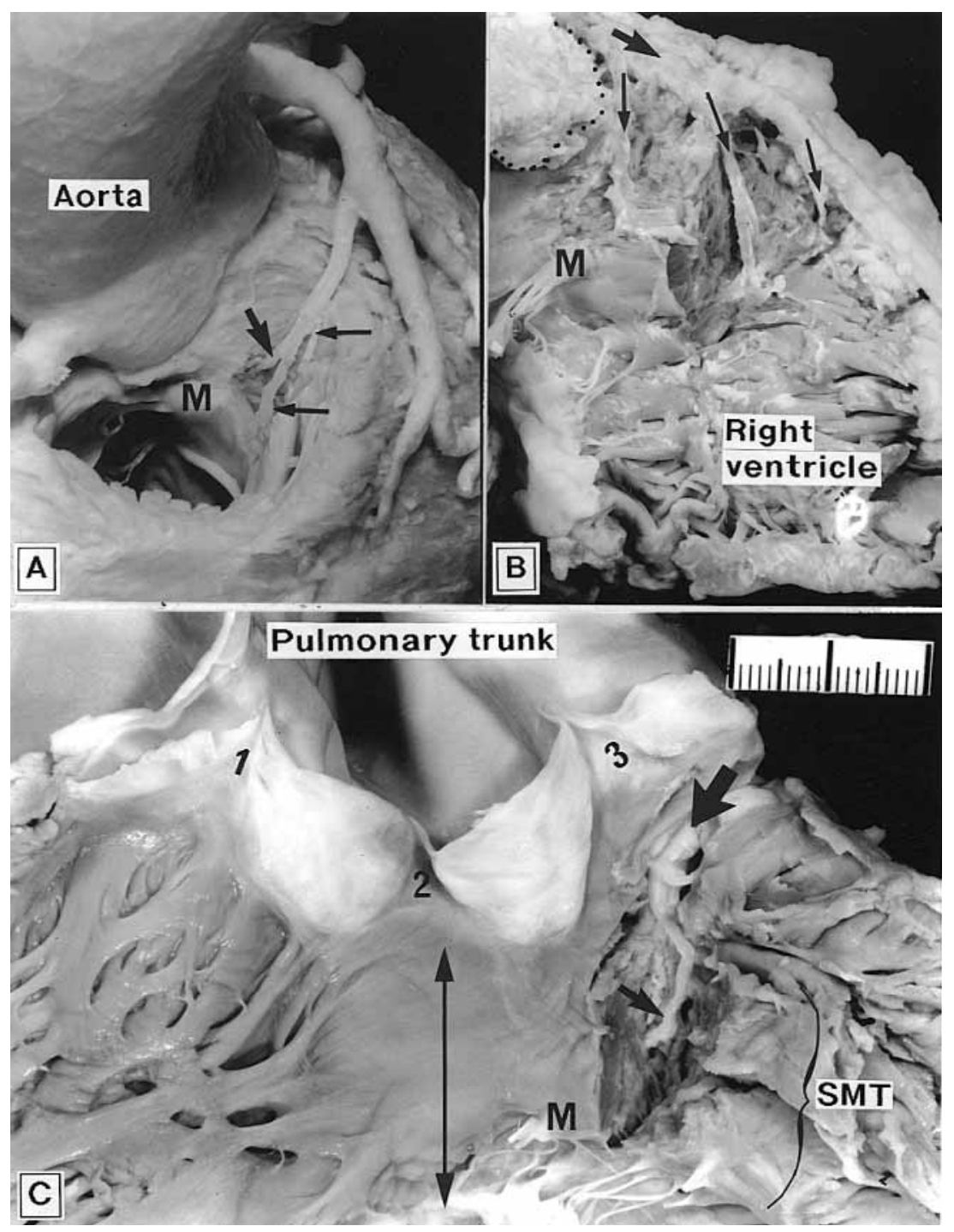

Fig 1. A, The course of the first septal perforating artery is displayed after removal of the pulmonary trunk and the subpulmonary infundibulum. The artery branches into three (arrows). The main branch (large arrow) passes toward the medial papillary muscle $(M)$ and the other 2 pass into the septomarginal trabeculation. B, Three septal perforating arteries (small arrows) arising from the superior interventricular artery (large arrow) are shown in this dissection. The first septal artery courses close to the aortic root (dotted line). $\mathbf{C}$, The right ventricular outflow tract is opened and displayed to show the proximity of the first septal perforating artery (small arrow) and its origin (large arrow) relative to the leaflets of the pulmonary valve. The anterior limb of the septomarginal trabeculation (SMT) has been removed. Double arrows indicate the "septal" component of the ventriculoinfundibular fold that, together with the subpulmonary infundibulum, forms the supraventricular crest. 1, 2, and 3 are fibrous interleaflet triangles. 2 is the triangle adjacent to (or facing) the aortic valve.

their disposition in the malformed heart, ${ }^{4}$ despite the potential for damage in operations such as the Ross procedure, correction of tetralogy of Fallot, resection of obstructive muscular subaortic stenosis, and enlargement of restrictive ventricular septal defects (VSDs) in settings such as double-outlet right ventricle, double- inlet left ventricle, and tricuspid atresia. Nonetheless, damage to these vessels can result in myocardial damage and arrhythmias. ${ }^{1}$ In this study, therefore, we sought to establish landmarks to permit the prediction of the precise origin and distribution of the septal perforating arteries in normal and congenitally malformed hearts. 


\section{Methods}

We studied 50 hearts, specifically 9 normal hearts, 10 with tetralogy of Fallot, 7 with double-outlet right ventricle and subaortic VSDs, 6 with double-outlet right ventricle and subpulmonary VSDs, 6 with double-inlet left ventricle, 6 with tricuspid atresia, and 6 hearts with an "isolated" VSD. The hearts were dissected to display the origin and course of the septal perforating arteries, with magnification of $2.5 \times$ or $3.5 \times$ depending on the size of the hearts.

We recorded the number of superior septal perforating arteries, the relationship between the first septal and the first diagonal arteries, and the relationship between the first septal artery and the freestanding infundibular structures, which are freestanding muscular sleeves that arise from ventricular musculature and support the leaflets of the arterial valves (Fig 1). Such infundibula can be bilateral, as typically seen in double-outlet right ventricle, subpulmonary, as in the normal heart, or subaortic, as typically seen in complete transposition. Because of their proximity to the muscular ventricular septum, incisions made in the infundibulum represent a potential danger to the septal structures and hence to the perforating arteries. We studied, therefore, the distance between the first septal perforating artery and the freestanding infundibular sleeves.

The superior septal perforating arteries were located by dissecting the ventricular septum from its right ventricular aspect. The muscle fibers were gently stripped away until the arteries became visible. The depth of the vessel was then measured perpendicularly with respect to the right ventricular endocardium. The arteries were followed sufficiently far to determine their relationship with respect to 3 easily identifiable structures, namely the crest of the muscular ventricular septum, the muscular outlet septum, and the medial papillary muscle. The muscular outlet septum is the musculature that interposes between the subarterial outflow tracts. In the normal heart it is not possible with any certainty to distinguish such a discrete muscular outlet septum from the remainder of the muscular septum and the freestanding subpulmonary infundibulum. In congenitally malformed hearts, in contrast, the outlet septum can be substantial and is readily distinguished from both the remainder of the muscular ventricular septum and the other infundibular structures.

In addition to dissecting the superior perforating arteries, we also excised for additional histologic studies that part of the septal tissues estimated to contain the atrioventricular node, the bundle of His, and the branching atrioventricular bundle. For this purpose we studied 3 normal hearts, 3 hearts with an isolated VSD, 3 with tetralogy of Fallot, 3 with double-outlet right ventricle, 2 with double-inlet left ventricle, and 2 with tricuspid atresia. Serial histologic sections were made parallel to the diaphragmatic surface of the heart. The sections were cut at $10-\mu \mathrm{m}$ thickness and were stained with Masson trichrome. Initially, every 50th section was examined to identify both the conduction tissues and the arteries supplying them. The arteries were then "traced" in both directions, that is, toward the superior and the inferior aspects of the heart to establish their origin. Occasionally it was necessary to look at every 10th section to trace smaller arteries.

\section{Results}

The ventricular septum received its blood from the septal perforating arteries. These are branches of the 2 arteries that delimit the septum, namely the superior and inferior interventricular arteries in hearts with 2 well-formed ventricles and the delimiting arteries in those with 1 dominant and 1 incomplete and hypoplastic ventricle. The septal perforating arteries varied in size and number and arose at varying points along the 2 "parent" arteries. They traveled within the septum close to the right ventricular endocardium. Those arising superiorly were much larger and more numerous. Those arising inferiorly were usually not more than small twigs, except in hearts with double-inlet left ventricle, in which they were noticeably larger but still smaller than their superior counterparts.

The number of septal arteries arising from the superior interventricular or from the superior delimiting arteries ranged from 1 to 10 , with an average of 4.2. They varied markedly in size; many of them were no more than small twigs. Taking account of only the large septal arteries, the number varied from 1 to 4 , with an average of 1.7. Large septal arteries have been previously defined as those with a minimum diameter of 1 mm. ${ }^{3,4}$ In our series the specimens studied varied greatly in size. In the very small specimens the arteries were proportionately small. Consequently, it was not possible to apply the same rule to distinguish large septal arteries in all hearts. Our distinction, therefore, was subjective based on the relative size of the vessels.

The number of septal branches arising from the inferior interventricular and the inferior delimiting arteries ranged from 0 to 7 , with an average of 2 . In 4 hearts these included the terminal part of the parent artery, which irrigated the septum as a perforating artery. In 40 hearts these branches were all very small. In 10 hearts, however, there was at least 1 relatively large septal branch.

Only for the superior arteries were we able to distinguish specific anatomic patterns. The largest superior septal branches always arose from the more proximal parts of the arteries as compared with the small branches. In 40 hearts $(80 \%)$ the largest vessel was either the first artery alone or the first of a series, all being the same size. This arrangement was seen in all 9 normal specimens. In 10 hearts the largest septal vessel was either the second or the third perforating artery. In these specimens the first septal artery was "cut short" by a ventricular septal deficiency. 

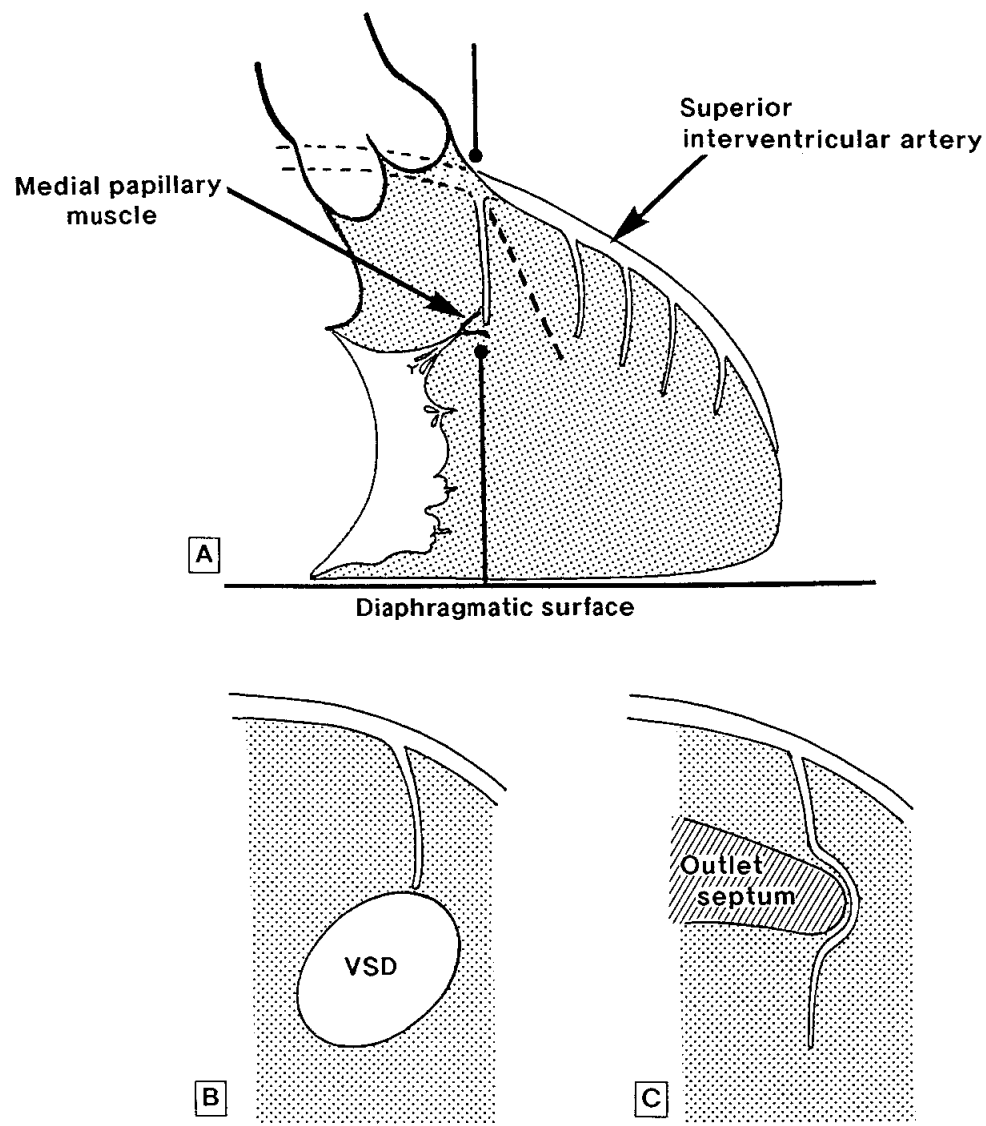

Fig 2. A, This diagram represents the dissection shown in Fig $1, B$. When the medial papillary muscle was present, the first septal artery tended to pass toward the base of the medial papillary muscle. The origin of the septal artery corresponds to a perpendicular line (-) joining the base of the medial papillary muscle to the diaphragmatic surface. In the absence of a medial papillary muscle, the first septal artery takes a more oblique course (single broken line). B, The septal artery cannot be traced beyond the anterosuperior rim of the VSD. C, The path of the septal artery is deviated by the septal insertion of the outlet septum.

The relationship between the first septal and the first diagonal arteries was very variable; the origin of the septal artery was from $26 \mathrm{~mm}$ proximal to the first diagonal to $12 \mathrm{~mm}$ distal to it. The depth of the first superior septal artery within the septum, as measured from the right ventricular aspect, also varied, with a range from 1 to $13 \mathrm{~mm}$. There was considerable variation between, as well as within, the hearts.

The relationship of the first superior septal artery to the infundibulum. In hearts with normal ventriculoarterial connections and relations, there was a constant relationship between the first superior septal artery and the pulmonary valve. After its takeoff from the superior interventricular artery, the first perforating artery approached the subpulmonary infundibulum immediately beneath the leftward of the 2 pulmonary sinuses adjacent to the aorta. In adult hearts it penetrat- ed the septum at a level 7 to $9 \mathrm{~mm}$ below the nadir of the hinge of the pulmonary valvular leaflet. The artery passed into the musculature between this nadir and the interleaflet triangle between the leftward and nonadjacent sinuses, running a few millimeters beneath the endocardial surface of the right ventricular outflow tract (Fig 1). This area was related to the anterior limb of the septomarginal trabeculation.

The arterial pattern in normal hearts. In 8 of the 9 normal hearts the path of all septal arteries was relatively straight, with the first superior artery coursing toward the base of the medial papillary muscle, which was present in all 9 specimens. It then terminated at the base of the muscle or else became too small to be traced farther (Fig 1). In 1 of these 8 cases the second septal artery also gave a large branch that terminated at the base of the medial papillary muscle. In the remaining 1 normal 

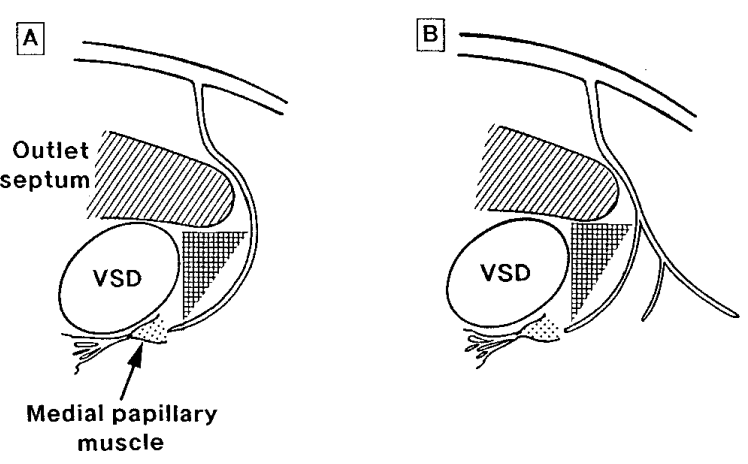

Fig 3. In the presence of an outlet septum and a VSD the septal artery passes directly toward the base of the medial papillary muscle (A) or branches $(\mathbf{B})$. There is a small area (hatched) that is devoid of large arteries.

specimen, the course of the first septal artery was also straight but not toward the base of the medial papillary muscle. Instead, the vessel traveled obliquely and anteriorly but gave rise to a large branch that extended toward the base of the medial papillary muscle. In all 9 normal hearts the origin of the first superior septal perforating artery was perpendicularly above the base of the medial papillary muscle. Thus, with the heart in an anatomic position, an imaginary line drawn perpendicular to the inferior, diaphragmatic surface of the heart that traveled through the base of the medial papillary muscle crossed the superior interventricular artery at the site of origin of its first septal perforating branch (Fig 2). There were no septal arteries closer to the infundibular structures than this perpendicular line.

The septal arterial pattern in congenitally malformed hearts. The basic pattern of the perforating arteries was similar in the congenitally malformed hearts to that seen in normal hearts, albeit perturbed by the presence or absence of a medial papillary muscle, the insertion of the muscular outlet septum onto the remainder of the muscular ventricular septum, and by areas of ventricular septal deficiency.

The medial papillary muscle was present in 20 congenitally malformed hearts. The first septal artery terminated at its base in 13 of these 20 hearts. In the remaining 7 hearts the vessel traveled obliquely anteriorly but gave rise to a large branch that extended posteriorly toward the base of the muscle. In 5 of these 20 hearts the first 2 septal arteries both terminated at the base of the muscle. Indeed, in 1 heart the first 3 septal branches behaved in this manner. In the 21 hearts lacking any medial papillary muscle, the septal perforating arteries extended anteriorly in a more oblique fashion, and their exact position was less predictable (Fig 2). There were no distinct landmarks.

It was possible, nonetheless, to observe a perpendicular relationship between the medial papillary muscle when present and the first septal artery in a manner comparable with that seen in the normal heart. In 17 of the 20 malformed hearts in which the muscle was present, the origin of the first septal perforating artery was located perpendicularly above the base of the muscle (Fig 2, A). This rule, however, was broken in 3 hearts. In 1 heart with a VSD, the origin of the first septal artery was $2 \mathrm{~mm}$ distal to its predicted site. In 1 heart with double-outlet right ventricle, it was the second septal perforating artery that obeyed the rule; the first artery arose much more proximally and traveled obliquely in the direction of the apex of the heart without giving any branch to the medial papillary muscle. In another heart with double-outlet right ventricle, the first and second septal perforating arteries were both substantial and arose within $2 \mathrm{~mm}$ of each other. The constructed perpendicular line then passed between the two. Thus, in 18 of the 20 hearts that possessed a medial papillary muscle, there were no septal arteries closer to the infundibular structures than the constructed perpendicular line.

The septal perforating arteries generally followed a straight course unless they encountered an obstacle. Such obstacles could be an area of ventricular septal deficiency or the insertion of the muscular outlet septum onto the remainder of the ventricular septum. In all 12 hearts with univentricular connection to a dominant left ventricle, including all those with double-inlet or tricuspid atresia, the first septal artery terminated at the border of the VSD. No vessel was found to deviate and travel around the defect. In contrast, in all situations in which the superior septal perforating arteries encountered the muscular outlet septum, they deviated apically and skirted around it, never entering the outlet septum (Fig 2, $B$ and $C$ ).

In 11 hearts an area of a ventricular septal deficiency, the muscular outlet septum, and the medial papillary muscle were all present (Fig 3). In all these hearts it was possible to predict the resultant path of the first septal artery relative to each individual feature. Thus, the first septal artery took its origin perpendicularly above the base of the medial papillary muscle. The artery was then deviated apically by the muscular outlet septum. Having cleared the outlet septum, the artery either turned back and terminated at the base of this muscle ( 5 cases) or gave rise to a large branch that itself terminated at the muscle (6 cases). This left a triangular area on the crest of the muscular ventricular septum 
that was free of major arteries. This triangle is bordered by the outlet septum, the medial papillary muscle, and the muscular margin of the VSD (Fig 3).

Histologic studies. Histologic studies were performed in 16 hearts. In the 2 hearts with double-inlet left ventricle, the anteriorly located atrioventricular node, bundle of His, and the atrioventricular bundle received the entirety of their blood supply from the delimiting right and superior interventricular coronary artery. In the other 14 hearts the atrioventricular node always received its blood supply from the inferior interventricular artery. The bundle of $\mathrm{His}$ and the branching atrioventricular bundle also received their blood supply from the inferior interventricular artery in 10 of the 14 hearts. In 3 cases ( 1 normal, 1 with a VSD, and 1 with double-outlet right ventricle), the major supply came from the superior interventricular artery, and in 1 case with double-outlet right ventricle from both superior and inferior interventricular arteries.

\section{Discussion}

It is now the rule to anticipate excellent results for the surgical repair of most forms of congenital heart disease. ${ }^{5-10}$ If further advances are to be made, they will depend on small increments produced by the refinement of techniques and procedures. One such attention to detail could be avoidance of damage to the first superior septal perforating artery, a complication that is known to be responsible for some of the problems that still occur subsequent to intracardiac surgery. These include ventricular dysfunction, arrhythmias, and sudden death. ${ }^{1,6,10-14}$ Our study has shown that landmarks do exist to permit the surgeon to determine where in the septum, if necessary, incisions can be made and where sutures can be placed without damaging the first septal perforating artery.

Interest in the blood supply of the ventricular septum is not new. As long ago as 1958, James and Burch ${ }^{2}$ studied 43 normal hearts, showing that the muscular ventricular septum received almost all its blood supply from the "anterior descending" coronary artery. Further interest in the vascular supply to the ventricular septum was then fueled by the evolution of the Ross procedure. ${ }^{1}$ The major complications of this operation in the early days were related to ventricular dysfunction and arrhythmias, themselves reflecting damage to the first septal perforating artery. The study of Geens and colleagues ${ }^{1}$ confirmed the findings of James and Burch but provided more detail, showing the close relationship of the first septal perforating artery to the pulmonary valve. In another study, Melo and colleagues ${ }^{3}$ studied 30 structurally normal hearts. They showed that the first septal perforating artery crossed the lower border of the anterior limb of the septomarginal trabeculation. They also noted for the first time that this vessel terminates at the base of the medial papillary muscle of the tricuspid valve. In a later study ${ }^{4}$ they extended these findings to hearts with aortic valvular disease and tetralogy of Fallot.

Our findings endorse the recommendation of Melo and colleagues, ${ }^{3,4}$ namely to use the medial papillary muscle as a landmark for the prediction of the site of termination of the first septal perforating artery, with the reservation that occasionally it is not the vessel itself but its largest branch that terminates there. We have now shown also that this landmark predicts the origin of the vessel, which is perpendicularly above the base of the muscle. In their study Melo and colleagues ${ }^{3}$ asserted that the first septal artery originated at the level of the first diagonal artery. In the hearts in our study, however, the diagonal artery was an unreliable landmark. When present, the medial papillary muscle and the constructed line perpendicular through its base were much better guides to the proximal course of the first septal artery. Melo and colleagues ${ }^{3,4}$ advocated the use of the anterior limb of the septomarginal trabeculation as a landmark for the perforating artery in normal hearts as well as hearts with aortic valvular disease and tetralogy of Fallot. We endorse this suggestion. Indeed, this landmark coincides with the constructed perpendicular line used in this study, although it is not always easily distinguishable on the endocardial surface and its size is variable. Because of this, it proved to be a less accurate guide than our constructed line.

In many congenitally malformed hearts the pattern of septal arterial supply is disturbed by the presence of a VSD and by a muscular outlet septum deviated into the right ventricle. Resection of musculature to relieve subpulmonary stenosis in tetralogy of Fallot can be guided by the above anatomic landmarks to avoid damage to the large septal artery. Equally, enlargement of a restrictive VSD in various malformations can be made in the musculature between the medial papillary muscle and the outlet septum, bearing in mind the proximity of the septal artery to the leading margin of the outlet septum (Fig 2). In the modified Konno procedure for relief of left ventricular outflow obstruction with preservation of the aortic valve, access to the left ventricle is gained through an incision in the upper part of the muscular ventricular septum. ${ }^{15,16}$ If the septal incision is made along the length of the septomarginal trabeculation, the risk of trauma to the major septal artery is increased compared with a transverse incision that runs parallel to our line constructed as the guide to the 
course of the septal artery. It is significant that heart block developed in the index case in which the modified Konno procedure was used. ${ }^{15}$ It seems likely that this complication was related to trauma to the artery supplying the bundle of His rather than to direct damage to the conduction tissues.

Our study has its limitations. The dissection and measurements were done in hearts that had been fixed in formaldehyde. Although every effort is made to preserve the natural shape of the heart during the fixing process, the fact remains that the live heart is softer and its different parts more mobile with respect to each other. It is possible, therefore, that the alignment of cardiac structures could be less obvious, or even different, in the relaxed heart under cardioplegic arrest. The pattern of septal blood supply found in this study, nonetheless, was so consistent that it would be difficult to imagine it being a chance occurrence as a result of the fixing process.

We thank Ms Karen McCarthy, Miss Zarlasht Najem, and Mr Vi-Hue Tran for their help and technical support with the preparation of the figures.

Received for publication Oct 20, 2000; revisions requested Nov 24, 2000; revisions received Dec 6, 2000; accepted for publication Dec 9, 2000.

Address for reprints: S. Y. Ho, PhD, FRCPath, National Heart and Lung Institute, Imperial College of Science, Technology and Medicine, Dovehouse St, London SW3 6LY, United Kingdom (E-mail: yen.ho@ic.ac.uk).

\section{REFERENCES}

1. Geens M, Gonzales-Lanvin L, Dawbarn C, Ross DN. The surgical anatomy of the pulmonary artery root in relation to the pulmonary valve autograft and surgery of the right ventricular outflow tract. J Thorac Cardiovasc Surg 1971;62:262-7.

2. James TN, Burch GE. Blood supply of the human interventricular septum. Circulation 1958;17:391-6.

3. Melo JQ, Abecassis M, Neves JS, Calquinha J, Ramos S, Martins $\mathrm{AP}$, et al. Can the location of the large septal artery be predicted? Eur J Cardiothorac Surg 1995;9:628-30.
4. Melo JQ, Abecassis ME, Neves JS, Bruges LO, Ramos SB, Martins AP. The large septal arteries in normal hearts, in aortic valve disease, and in tetralogy of Fallot. Ann Thorac Surg 1995;60(Suppl):S626-8.

5. Meijboom F, Szatmari A, Utens E, Deckers JW, Roelandt JR, Bos E, et al. Long-term follow-up after surgical closure of ventricular septal defect in infancy and childhood. J Am Coll Cardiol 1994;24:1358-64.

6. Abramov D, Snir E, Abramov Y, Raanani E, Birk E, Vidne B. Definitive repair of tetralogy of Fallot: a review of 104 cases. Scand J Thorac Cardiovasc Surg 1995;29:195-200.

7. Morris CD, Menashe VD. 25-year mortality after surgical repair of congenital heart defect in childhood: a population-based cohort study. JAMA 1991;266:3447-52.

8. Nollert G, Fischlein T, Bouterwek S, Bohmer C, Klinner W, Reichart B. Long-term survival in patients with repair of tetralogy of Fallot: 36-year follow-up of 490 survivors of the first year after surgical repair. J Am Coll Cardiol 1997;30:1374-83.

9. Rossi AF, Seiden HS, Sadeghi AM, Nguyen KH, Quintana CS, Gross RP, et al. The outcome of cardiac operations in infants weighing two kilograms or less. J Thorac Cardiovasc Surg 1998;116:28-35.

10. Zhao HX, Miller DC, Reitz BA, Shumway NE. Surgical repair of tetralogy of Fallot: long-term follow-up with particular emphasis on late death and reoperation. J Thorac Cardiovasc Surg 1985;89:204-20.

11. Shen WK, Holmes DR Jr, Porter CJ, McGoon DC, Ilstrup DM. Sudden death after repair of double outlet right ventricle. Circulation 1990;81:128-36.

12. Gatzoulis MA, Till JA, Sommerville J, Redington AN. Mechanoelectrical interaction in tetralogy of Fallot: QRS prolongation relates to right ventricular size and predicts malignant ventricular arrhythmias and sudden death. Circulation 1995;92:2317.

13. Sunakawa A, Shirotani H, Yokoyama T, Oku H. Factors affecting biventricular function following surgical repair of tetralogy of Fallot. Jpn Circ J 1988;52:401-10.

14. Sullivan ID, Presbitero P, Gooch VM, Aruta E, Deanfield JE. Is ventricular arrhythmia in repaired tetralogy of Fallot an effect of operation or a consequence of the course of the disease? A prospective study. Br Heart J 1987;58:40-4.

15. Cooley DA, Garrett JR. Septoplasty for left ventricular outflow obstruction without aortic valve replacement: a new technique. Ann Thorac Surg 1986;42:445-8.

16. Jahangiri M, Nicholson IA, del Nido PJ, Mayer JE, Jonas RA. Surgical management of complex and tunnel-like subaortic stenosis. Eur J Cardiothoracic Surg 2000;17:637-42. 